\title{
Combination of stem cell therapy and acupuncture to treat ischemic stroke: a prospective review
}

\author{
Huidong Jia ${ }^{1,4+}$, Jia He ${ }^{2,3 \dagger}$, Lan Zhao ${ }^{2,3}$, Chia-Chen Hsu ${ }^{4}$, Xiaofeng Zhao ${ }^{2,3}$, Yuzheng Du ${ }^{2,3}$, Lin Han²,3, \\ Zhanfeng Cui ${ }^{1,4}$, Xuemin Shi ${ }^{2,3+}$ and Hua Ye $\mathrm{P}^{1,4^{*}+}$ (B)
}

\begin{abstract}
Stroke is the second leading cause globally that leads to severe disability and death. Stem cell therapy has been developed over the recent years to treat stroke and diminish the mortality and disability rate of brain injuries. Acupuncture, which can activate endogenous recovery via physical stimuli, has been applied to enhance the recovery and rehabilitation of stroke patients. Attempts have been made to combine stem cell therapy and acupuncture to treat stroke patients and have shown the promising results. This prospective review will look into the possible mechanisms of stem cell therapy and acupuncture and intend to undercover the potential benefit of the combined therapy. It intends to bridge the modern emerging stem cell therapy and traditional acupuncture at cellular and molecular levels and to demonstrate the potential benefit to improve clinical outcomes.
\end{abstract}

Keywords: Ischemic stroke, Stem cell therapy (cytotherapy), Acupuncture, Combination therapy

\section{Background}

Stroke is the second leading cause of mortality and disability of adults all over the world, which caused 5.5 million deaths globally in 2016 [1]. In adults, ischemic stroke represents about $87 \%$ of stroke cases [2]. The pathophysiologic processes of brain neural tissue death and vasogenic edema occurring in ischemic stroke result from exposing the brain to reduced oxygen levels (hypoxia) and/or blood supply (ischemia), and the secondary excitotoxicity and oxidative stress in the acute phase, following the apoptosis and inflammatory damage in the subacute phase, resulting in dyskinesia, aphasia, sensory

\footnotetext{
*Correspondence: hua.ye@eng.ox.ac.uk

${ }^{\dagger}$ Huidong Jia and Jia He are joint first author

${ }^{+}$Xuemin Shi and Hua Ye are joint corresponding author

${ }^{1}$ The Oxford Suzhou Centre for Advanced Research (OSCAR), Building

A, 388 Ruo Shui Road, Suzhou Industrial Park, Jiangsu, People's Republic of China

Full list of author information is available at the end of the article
}

disturbances, ataxia sequelae symptoms, or even death $[3,4]$.

Current treatments for stroke mainly focus on neuroprotection and recanalizing obstructed cerebral blood vessels, which include hypothermia and the administration of antithrombotic, antiplatelet, and antihypertensive drugs for ischemic brain damage caused by an embolism (Fig. 1) [5-7]. Although these treatments could partly prevent brain injury progression through reduction of metabolic demands, suppression of excitotoxicity, and free radical activity [8], the 6-h rescue time window limits the efficiency, and none of the treatments can promote neuro-regeneration, which aims to replace the dead neurons and to rebuild a functional neuronal network in order to contribute to behavioral improvements $[9,10]$.

In the last two decades, stem cells, with their capability to self-renew and differentiate into multiple cell derivatives, have shed light on treating stroke [5]. A wide variety of different stem cell types have been used in experimental and clinical studies in a variety of applications, original author(s) and the source, provide a link to the Creative Commons licence, and indicate if changes were made. The images or other third party material in this article are included in the article's Creative Commons licence, unless indicated otherwise in a credit line to the material. If material is not included in the article's Creative Commons licence and your intended use is not permitted by statutory regulation or exceeds the permitted use, you will need to obtain permission directly from the copyright holder. To view a copy of this licence, visit http://creativecommons.org/licenses/by/4.0/. The Creative Commons Public Domain Dedication waiver (http://creativeco mmons.org/publicdomain/zero/1.0/) applies to the data made available in this article, unless otherwise stated in a credit line to the data. 


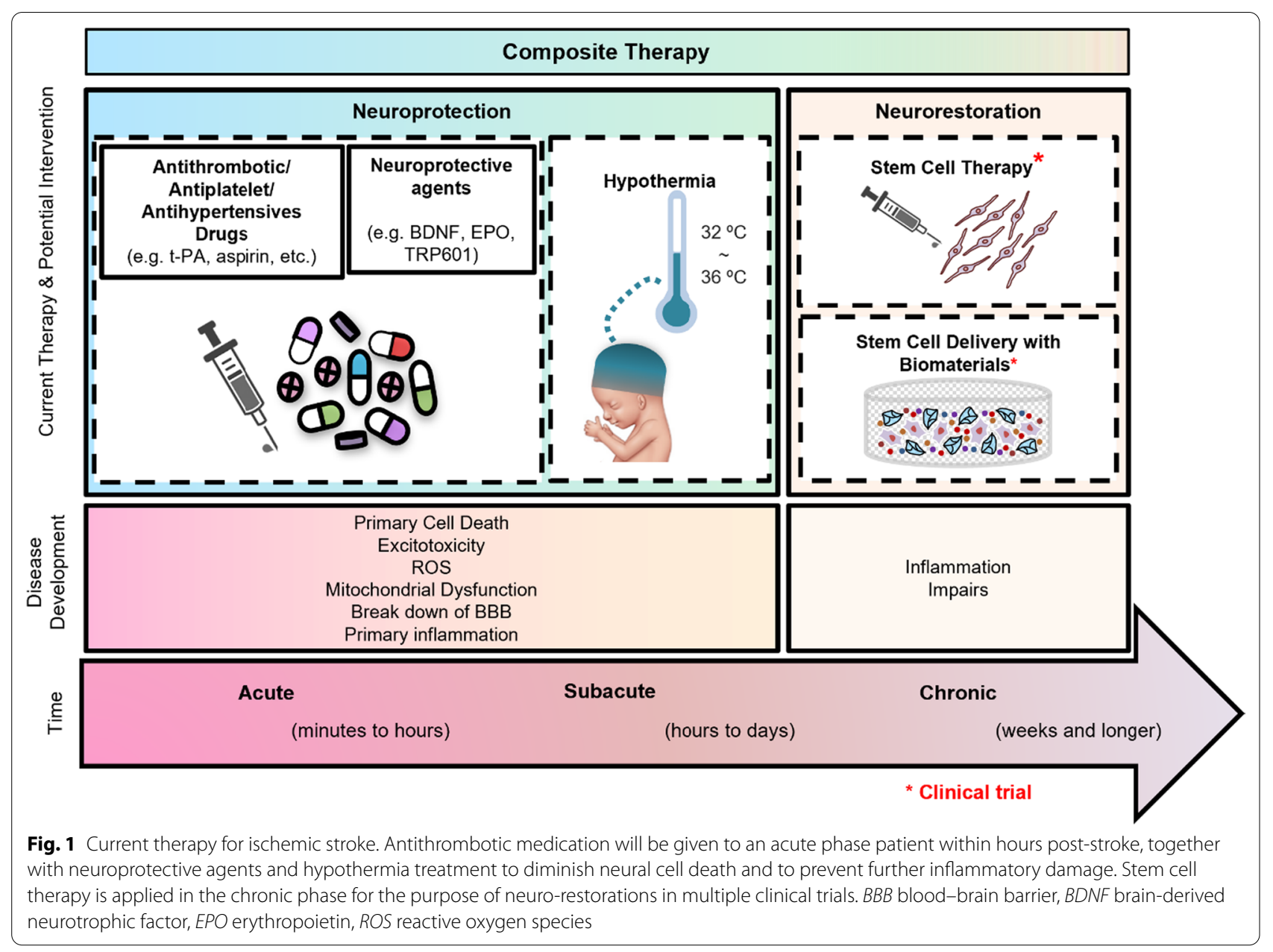

including cell replacement, activation of endogenous neurogenesis and angiogenesis, neuroprotection, and modulation of inflammation and immune responses for the regeneration of the lost cells and enhancement of neurogenesis to improve long-term recovery [11-13].

Acupuncture has been used in stroke management for more than thousands of years in China. Random controlled clinical trials showed that acupuncture ameliorate post-stroke paralysis, ataxia, shoulder pain, aphasia, and dysphagia, promoting rehabilitation and reducing fatality rates [14-19].

An overview of stem cell therapy and acupuncture for stroke treatment and the mechanisms behind their effects will be summarized in this review, which aims to explore their intrinsically cooperative therapeutic effects. Clinical trials using cell-based therapies and acupuncture for stroke patients will be evaluated and a series of cellular products currently under development will be highlighted. Finally, we will discuss the benefit and possibility of developing a new stroke therapeutic strategy combing implantation of functional cells and acupuncture as a potential complementary therapy to other conventional treatments. The administration protocol for clinical stem cell therapy, for example the cell dose or administration route of the therapy, is not the focus of this study due to the lack of sufficient clinical data for randomized controlled trials (RCTs).

\section{Stem cell therapy for ischemic stroke}

Studies of stem cell therapy for ischemic stroke have mostly focused on two different mechanisms: (1) replacement of damaged neural cells and tissues and (2) paracrine functional effects including immunomodulation, pro-angiogenesis, and neuroprotective and neurotrophic functions [20, 21]. Broadly, embryonic stem cells (totipotent stem cells), fetal stem cells (mainly the fetal brain or spinal cord derived-neural stem cells), adult stem cells (tissue-specific stem cells, such as mesenchymal stem cells), and induced pluripotent stem cells (genetically engineered stem cells) are the most preclinically and clinically tested cell types in the ischemic stroke regenerative 
therapy. The clinical trials of cell therapy for stoke are summarized in the Additional file 1.

\section{Cell types in stroke cytotherapy (Table 1)}

Embryonic stem cells (ESCs) are derived from the inner cell mass of the blastocyst and are characterized by selfrenewal and the ability to differentiate into cell derivatives of all three germ layers. In particular, clinically relevant neural lineage cells, such as cortical neurons, motor neurons, astrocytes, oligodendrocytes, and other neural cell types, have successfully been derived from human ESCs [21-23]. However, ethical concerns and tumorigenesis are the major obstructs hindering the ESCs from entering human clinical trials.

Induced pluripotent stem cells (iPSCs) are reprogramed from somatic cells, such as fibroblasts, into a stem cell state with self-renewal capacity and pluripotency similar to ESCs. However, unlike ESCs, iPSCs can bypass certain ethical issues and can be used to derive patient-specific cells, which can lower the risk of immune rejection [24]. There has been extensive research on robust protocols to generate neuronal and glial lineages from human iPSCs [25-27]. iPSCs has been recognized as one of the best regenerative medicine resources if the tumorigenesis risk could be removed or under control.

Neural stem cells (NSCs) sources can be endogenous or exogenous. Cells used to generate endogenous NSCs are adult NSCs located in the subventricular zone, the hippocampal dentate gyrus, and the olfactory bulb [11]. Previously, studies have shown that a limited number of endogenous NSCs can be activated and recruited to an infarcted area to promote neuro-regeneration [28]. Exogenous NSCs are derived from exogenous pluripotent stem cells (as discussed above in the ESCs and iPSCs sections), bone marrow-derived multipotent stem cells, or isolated from fetal and adult nervous systems [29-31]. Preclinical and clinical trials of commercialized engineered NSC lines, such as NSI-566 (human fetal spinal cord-derived NSC line) from Neuralstem Inc and CTX cell line (immortalized NSC line from brain frontal cortex tissue by c-mycER ${ }^{\text {TAM }}$ technique) from $\mathrm{ReNeu}$ ron Ltd., have reported promising outcomes for treating stroke [32, 33].

Mesenchymal stem cells (MSCs) are multipotent stem cells that can be derived from a wide range of tissues, commonly including umbilical cord blood, umbilical cord, placenta, bone marrow, and adipose tissues. They are a mixture of multi-cell populations with origin tissuespecific properties but share a similar phenotype and a plastic adherent proliferation pattern [34]. Although MSCs have been shown to differentiate into neural lineages in some studies, the neural regeneration mechanism behind this differentiation has mainly been attributed to trophic effects of angiogenesis, neurogenesis, as well as modulating the host immune response [35].

Other cell types: Perinatal tissues have become one of the major stem or progenitor cell sources, which are abundant and without ethical concerns [36, 37]. Mononuclear cells (MNCs) isolated from umbilical cord blood (UCB), comprising a mixture of more than three subpopulations of hematological stem cells (HSCs), endothelial progenitor cells (EPCs), and MSCs, have also shown some positive effects for ischemic stroke therapy in animal models and human clinical trials [38-41]. EPCs can differentiate into mature endothelial cells, which exert pro-angiogenesis effects and have been observed migrating to the boundary zones of ischemic infarcted areas of Sprague-Dawley rat brains when intravenously administered within 24-h post-middle cerebral artery occlusion (MCAO). EPCs were found to incorporate into blood vessels in ischemic tissues [42], indicating their potential for use in stroke cell therapies [43].

\section{Therapeutic mechanism of stem cell therapy}

In the early stage of cerebral ischemia, the main cause of the destruction of brain tissues is a cascade of damage

Table 1 Clinical trials of stem cell-based therapies to treat ischemic stroke

\begin{tabular}{|c|c|c|c|c|c|}
\hline Cell type & Advantage & Disadvantage & Administration Route & Implantation windows & References \\
\hline MSCs & $\begin{array}{l}\text { Abundant, Low ethical con- } \\
\text { cern, Low immunogenicity, } \\
\text { Multi-paracrine effects }\end{array}$ & $\begin{array}{l}\text { No neural cell or tissue } \\
\text { regeneration ability }\end{array}$ & $\begin{array}{l}\text { All available route }(\mathrm{IV}, \mathrm{IA} \text {, } \\
\mathrm{IT}, \mathrm{IP})\end{array}$ & $\begin{array}{l}\text { Acute phase, Less than } 6 \\
\text { months }\end{array}$ & {$[50-52]$} \\
\hline NSCs & $\begin{array}{l}\text { Neural cell replacement, } \\
\text { Neural tissue regeneration }\end{array}$ & $\begin{array}{l}\text { Limited sources and expan- } \\
\text { sion ability, } \\
\text { Ethical concern }\end{array}$ & Intracerebral & $\begin{array}{l}\text { Chronic phase, Not earlier } \\
\text { than } 1 \text { month }\end{array}$ & {$[35,53]$} \\
\hline iPSCs/iNSCs & $\begin{array}{l}\text { Sufficient neural cells, No } \\
\text { ethical concern, Paracrine } \\
\text { effects }\end{array}$ & $\begin{array}{l}\text { Genetically modified, Tumori- } \\
\text { genesis risk, Immunogenicity }\end{array}$ & $\begin{array}{l}\text { NRG_-Intracerebral } \\
\text { PE—any route }\end{array}$ & $\begin{array}{l}\text { NRG_chronic phase, PE_- } \\
\text { acute phase }\end{array}$ & {$[36,54]$} \\
\hline
\end{tabular}

NRG neural regeneration, $P E$ paracrine effect

IV, intravenous; IA, intraarterial; IT, intrathecal; IP, intraperitoneal; MSCs, mesenchymal stem cells; NSCs, neural stem cells; iPSCs, induced pluripotent stem cells; iNSCs, immortalized NSCs 
due to anoxic depolarization, excitotoxicity, oxidative stress, and necrosis. Protecting cells in the peri-infarct area from excitotoxicity and oxidative stress is of the highest priorities for the treatment in the early-stage of ischemic brain injury [44].

\section{Antioxidation and ionic homeostasis}

MSCs possess a great potential for treating early-stage ischemic brain injury because of their paracrine functions, tolerance, and adaptive capacity to the brain ischemic and hypoxia microenvironment. Kaneko et al. demonstrated a successful combinatorial treatment of hypothermia and MSCs for neuron protection in vitro and proposed the delta opioid pathway is a therapeutic mechanism of the stem cell therapy, which maintains ionic homeostasis and endogenous neuroprotection [45].

The mechanisms of stem cell paracrine functions in antioxidative properties have been studied by analyzing the antioxidant defense and scavenging effects of stem cell-conditioned media. Modulating the signaling pathway AKT/pAKT and ERK1/2/pERK, activating the antioxidant proteins (such as Keap1, Nrf2, and HO-1), and releasing the neurotrophic factors NGF and BDNF have been reported from different in vitro studies [46, 47]. Lee et al. also discovered that oxidative stress and glial activation level decreased in rats with Alzheimer's disease after receiving hUCB-MSC implantation, which resulted in learning and memory function improvement [48].

Pathological membrane hyperpolarization prevents correct functioning of the electron transport chain, resulting in mitochondrial failure, which is one of the major steps leading to BBB dysfunction, focal vascular destruction, and progressive neural cell death in the acute stages of ischemic stroke. Intercellular mitochondrial transfer has been identified as an important mechanism of tissue regeneration by providing a means to improve metabolism in damaged cells [49]. Boukelmoune et al. found the NSCs that uptake the labeled MSCs' mitochondria have more intact mitochondrial membranes and better mitochondria function in a co-culture system that contains neurotoxic factors, which suggests that the transferring of mitochondria exerts additional cell recovery benefits beyond the direct uptake of intact organelles [50].

\section{Immunomodulation}

MSCs have been demonstrated to be able to systemically suppress over-responsive immune reactions by modulating the production of pro- or anti-inflammatory factors and the activity of immune cells. IFN- $\gamma$ and IL-1 are crucial pro-inflammatory factors that can activate MSC immune-suppressive effects [51, 52]. The immunomodulatory effects of MSCs, via regulating T cell, B cell, dendritic cell, and natural killer (NK) cell activity, have been shown to prevent deleterious autoimmunity in ischemic tissues $[53,54]$. The MSCs implanted in the acute phase have been found to reduce the size of necrotic area and maintain motor functions through downregulating M1 macrophage/microglia activation and decreasing infiltration of $\gamma \delta \mathrm{T}$ cells, while increasing the presence of $\mathrm{CD} 4+T_{\text {regs }}$ and $T_{\text {reg }}$-associated cytokines, which play a neuroprotective role via secretion of anti-inflammatory cytokines like IL-10 $[55,56]$.

Another major mechanism by which MSCs modulate the immune response is establishing negative-feedback loops to suppress inflammatory activity and promote tissue regeneration. MSCs can activate M2 macrophages to produce anti-inflammatory cytokines IL-10 and perform phagocytic activity by producing cyclooxygenase 2 and indoleamine 2,3-dioxygenase, therefore, reducing neutrophil immersion and diminishing further damage to the injured tissue [57].

\section{Promoting vascular remodeling}

BBB plays a pivotal role in maintaining the homeostasis of central nervous system (CNS) as a protective semipermeable shelter, regulating the exchange of substances between the circulating blood and the brain [58]. The loss of BBB integrity is associated with worse stroke outcomes, leading to vasogenic edema, brain swelling, and even cerebral hemorrhage [59].

Implantation of MSCs and/or EPCs could aid in the reconstruction of astrocytic end-feet and tight junctions, via the secretion of proangiogenic growth factors, including vascular endothelial growth factor (VEGF), basic fibroblast growth factor (FGF-2), and transforming growth factor-beta (TGF- $\beta$ ), attenuation of immune cell infiltration, MMP9 downregulation, and VEGF-A signaling pathway modulation effects, to restore the integrity of BBB and the functional recovery of the cerebral vasculature at the acute phase of ischemic stroke [60-62].

\section{Pro-angiogenesis}

A key factor for neural regeneration and the restoration of cerebral function in stroke tissues in the postacute phase is revascularization of the necrotic zone and penumbra. Although both MSCs and EPCs produce necessary angiogenic factors, such as those in the FGF and VEGF families, MSCs are not directly involved in vasculature reconstruction like EPCs, but perform immunomodulation in the infarct region [63, 64]. Kang et al. revealed that pericytes coverage ratio is associated with angiogenesis with the use of a biomimetic vasculogenic model, which suggests that replenished multi-functional 
cells play a crucial role in balancing the immune response and revascularization in ischemic stroke therapy [65].

\section{Impaired neural tissue replacement}

Gliosis and gliotic scars enclose the necrotic infarct area at the post-stroke stage and the permanent neural tissue loss causes a series of neural dysfunctional symptoms. Only a limited number of endogenous NSCs can be activated by the signaling factors secreted from the lesion area to promote neuro-regeneration $[11,28]$. To achieve better neuroprotection and neurogenesis, researchers have genetically modified NSCs (gm-NSC) or applied iPSC-derived NSCs in neuroregenerative studies. Zhang et al. reported that intravenously transplanted bFGFexpression NSCs can survive, migrate, and differentiate into neurons and glial cells in a MCAO rat model. Their histological analysis indicated that endogenous NSCs are activated and involved in neural tissue regeneration [66]. Along with the extensive preclinical studies on ischemic stroke, a commercial gm-NSC line (CTX, ReNeuron Ltd.) has been used in the first-in-man trial via stereotactic ipsilateral putamen injection to treat patients that are 6-60 months after ischemic stroke. This open-label, single-site, dose-escalation study showed no adverse effects with improved neurological function [32].

\section{Stem cell therapy strategy and limitations in ischemic stroke treatment}

Stem cell therapy is considered a promising treatment for degenerative diseases and organ impairment. The clinical trials of cell therapy for stroke are summarized in Additional file 1: Supplementary Table 1. However, their curative effects on ischemic stroke are controversial as most of the relative clinical trials did not achieve the therapeutic targets that have been proved in animal studies. How to ensure the survival rate, maintain cell survival in vivo, improve target organ homing efficiency, differentiation ability, and paracrine functionality of the implanted stem cells are the major challenges in stem cell therapy [67, 68].

The means by which cells are delivered to stroke patients are selected based on the stage of the stroke and the desired therapeutic outcome. Multipotent stem cells are administered systemically via intravenous, intraarterial, intrathecal, and intraperitoneal routes when treatment via their paracrine effects is desired. Although systemic injection is a safe and convenient method to treat early-stage ischemic stroke patients, lung, liver, kidney, and spleen may clear or retain most of the implanted cells. Moreover, BBB prevents most of the leftover circulating stem cells from reaching the infarcted zone [13, 38].
Stem cell cerebral stereotactic implantation is an alternative cell treatment solution to improve neuroregeneration, developed following the progression of live-imaging technology (which improves the accuracy) and biomaterial technology (which increases the cell survival and homing rate by providing better cell carriers, such as injectable hydrogels). However, direct injection of stem cells into the brain is a risky procedure and can only be performed during the chronic stage of a stroke, after the infarction scar has already formed and the intracranial pressure returns to normal $[69,70]$.

Despite of the revolutionary equipment and technologies developed, it has remained a challenge to deliver cells to the intracerebral microenvironment of ischemic stroke patients due to the complexity of pathophysiological causes. Other factors resulting in low intracerebral migration and low homing rate are not due to immune rejection, but are due to ischemia, inflammation, oxidative stress in the wounded area and the presence of endogenous electric fields within the patient body [71]. In particular, high levels of ROS and free radicals in and around the infarcted area of the brain can induce cell death and dysfunction of the administered stem cells [72].

\section{Acupuncture to treat ischemic stroke}

Acupuncture has been served as an optional treatment in stroke rehabilitation. Clinical and laboratory evidence suggests that acupuncture induces multilevel regulation through complex mechanisms against cerebral ischemia, including: (1) neuroprotection, (2) collateral circulation reconstruction, (3) neuro-regeneration, and (4) modulating brain glucose metabolism and brain plasticity [73]. The data of acupuncture clinical trials for stroke treatment are summarized in Additional file 1: Supplimentary Table 2.

\section{Acupuncture methods in stroke}

In acupuncture, specific points on the body meridians are called acupoints. When acupoints are stimulated by needles, vital energy inside meridians is excited and produces the effects of dredging meridians, resulting in harmonizing the internal environment, attenuating the pathogenic factors, and may finally relieving symptoms or curing diseases [104]. There are many methods of acupuncture to treat stroke, but broadly, it falls into two major categories based on the intervention styles and techniques: manual acupuncture (MA) or electroacupuncture (EA). Acupuncture interventions have been applied at any stage in stroke progression and recovery after the patient's vital signs are stabilized. The therapeutic acupoint selection, schedule and course duration are 
variable depending on the seriousness of the illness and intervention time [74-81] (Fig. 2).

\section{Neuroprotective effects}

Unlike neuroprotective agents, acupuncture is a multitarget neuroprotective solution, which enhances endogenous neuroprotection functions to diminish brain edema and the volume of cerebral infarction, thus promoting the recovery of neural functions via the following therapeutic mechanisms.

\section{Attenuating inflammation}

Acupuncture can modulate inflammatory factors in brain tissues or peripheral blood that indirectly inhibit the activation of nuclear factor $\kappa B(N F-\kappa B)$, reduce the synthesis and secretion of pro-inflammatory cytokines, such as TNF- $\alpha$, Interleukin-6(IL-6), IL-8, IL-1 $\beta$, and TNF- $\alpha$, and at the meanwhile promote the secretion of anti-inflammatory cytokines IL-10. Acupuncture also attenuates the excessive activation of microglia, astrocytes, and macrophages [82-84].

\section{Attenuating the excitatory amino acids (EEAs)-induced toxicity}

Previous studies have shown that EA could reduce the accumulation of glutamate and aspartic acids in the topical cerebral infarct area and alleviate glutamate toxicity to neurons via regulating the expression of NMDARs and reducing $\mathrm{Ca}^{2+}$ influx in the hippocampus of cerebral ischemia/reperfusion injury rats $[85,86]$. Furthermore, EA pretreatment could play a neuroprotective role by enhancing the expression of glutamate receptor subunit 2 (GluR2) in the hippocampus after global cerebral ischemia (GCI) reperfusion through cannabinoid CB1 receptors (CB1R) [87]. In addition, EA pretreatment could also increase the expression of glutamate transporter-1 (GLT-1) and inhibit the excessive release of glutamate in the striatum during ischemic-reperfusion brain injury [88]. GABA-mediated inhibition also plays a role in acupuncture-induced reduction of excitotoxicity. There is evidence that acupuncture stimulation at GV26 could decrease excessive release of glutamate induced by ischemia and maintain the endogenous inhibitory activity of GABA [89].

\section{Inhibiting oxidative stress}

Acupuncture therapy possesses the potential to reduce oxidative stress caused by cerebral ischemia, which may be related to the neuroprotective effect of acupuncture [90]. Existing research showed that acupuncture could block the production of pro-oxidative stress factors, such as nitric oxide (NO), inducible nitric oxide synthase (iNOS), malondialdehyde(MDA), superoxide anion, and oxidized glutathione in mitochondria, while promoting the production of antioxidant factors, including superoxide dismutase (SOD), CuZnSOD, MnSOD, cyclooxygenase (COX), and reducing glutathione [91, 92]. Additionally, acupuncture also inhibits synthesis of translocase of the outer mitochondrial membrane 40 and translocase of the inner mitochondrial membrane 17A, as well as the accumulation of amyloid $\beta$ in brain mitochondria [91].

\section{Diminishing cell apoptosis}

Preclinical studies indicate that acupuncture could inhibit apoptosis, decrease infarct volume, and ameliorate neurological impairment via mechanisms mediated by different signaling pathways, such as PI3K/Akt and extracellular signal-regulated kinase (ERK)/c-Jun N-terminal kinase (JNK)/p38 [93, 94]. Acupuncture could also inhibit apoptosis after cerebral ischemia by increasing the expression of anti-apoptotic genes or protein B cell lymphoma 2 (Bcl-2), while reducing the expression of proapoptotic genes or proteins, including BCL-2-associated $\mathrm{X}$ (Bax, capase 3, and caspase 9) $[95,96]$.

\section{Regulating autophagy}

EA pretreatment at GV20 decreases the expression of autophagy markers and the number of autophagosomes in the ischemic cortex [97]. EA at GV20, GV4, and ST36 decreases the level of mammalian target of rapamycin (mTOR) and increases the levels of autophagy-related protein Beclin1 and LC3, which can inhibit neuronal injury induced by autophagy during the reperfusion period of cerebral ischemia [98]. Furthermore, EA at LI11 and ST36 could protect against focal cerebral ischemia by inhibiting autophagosome formation and autophagy, which is mediated via the mammalian target of rapamycin complex 1-Unc-51-like kinase (mTORC1-ULK) complex-Beclin1 pathway [99].

\footnotetext{
(See figure on next page.)

Fig. 2 Acupuncture method and intervention on stroke. a XingNaoKaiQiao (XNKQ) protocol, an acupuncture method for ischemic stroke treatment, includeing stimulating the main points to induce resuscitation and to tonify the liver and kidney and the supplementary points to dredge the meridians. $\mathbf{b}$ Acupuncture intervention may be applied in any stage of stroke with various therapeutic effects that promote the development of collateral circulation and prevent further brain damage at the acute phase and stimulate endogenous neurogenesis at the post-acute phase. BBB blood-brain barrier, MAVEA manual acupuncture/electrical acupuncture
} 

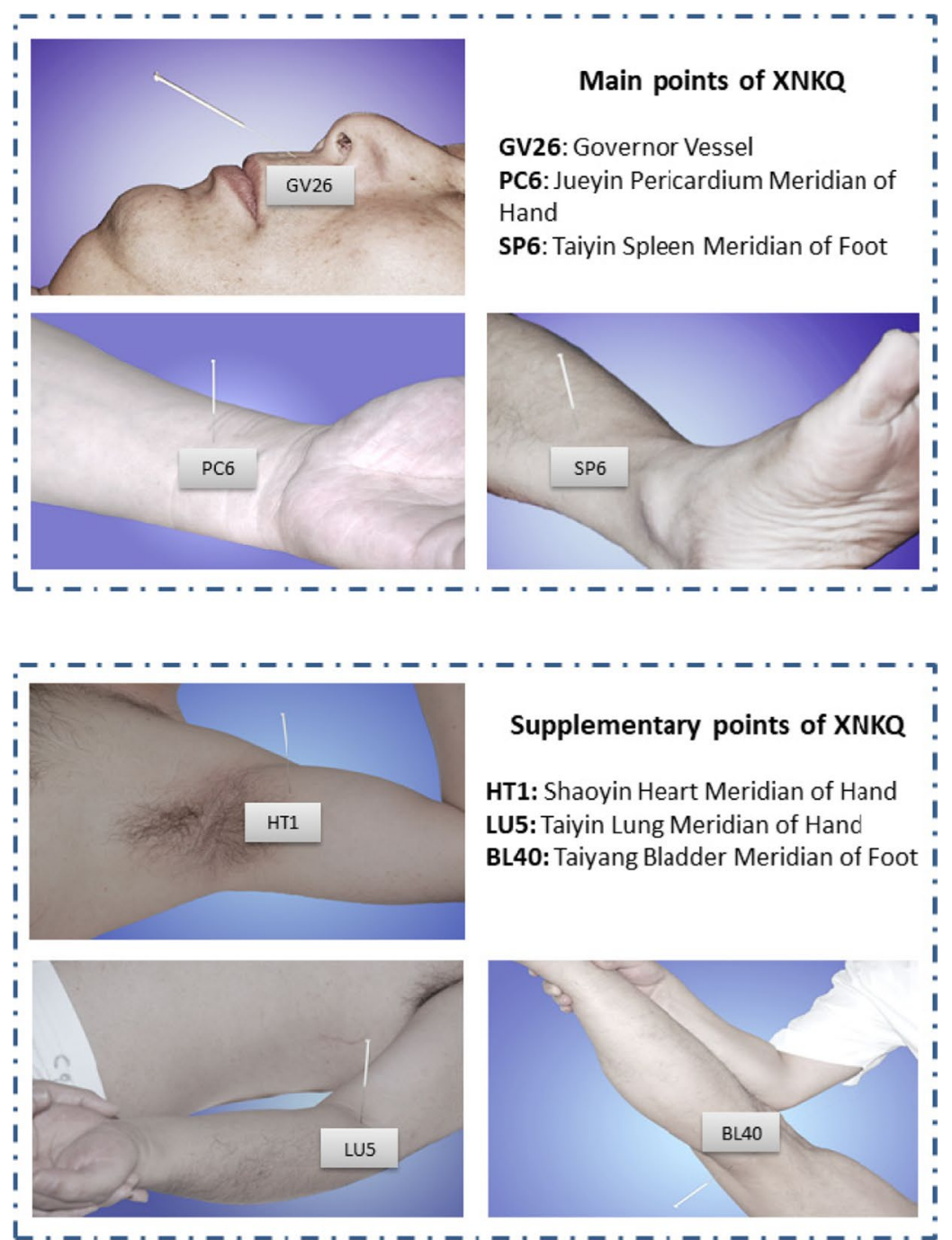

a

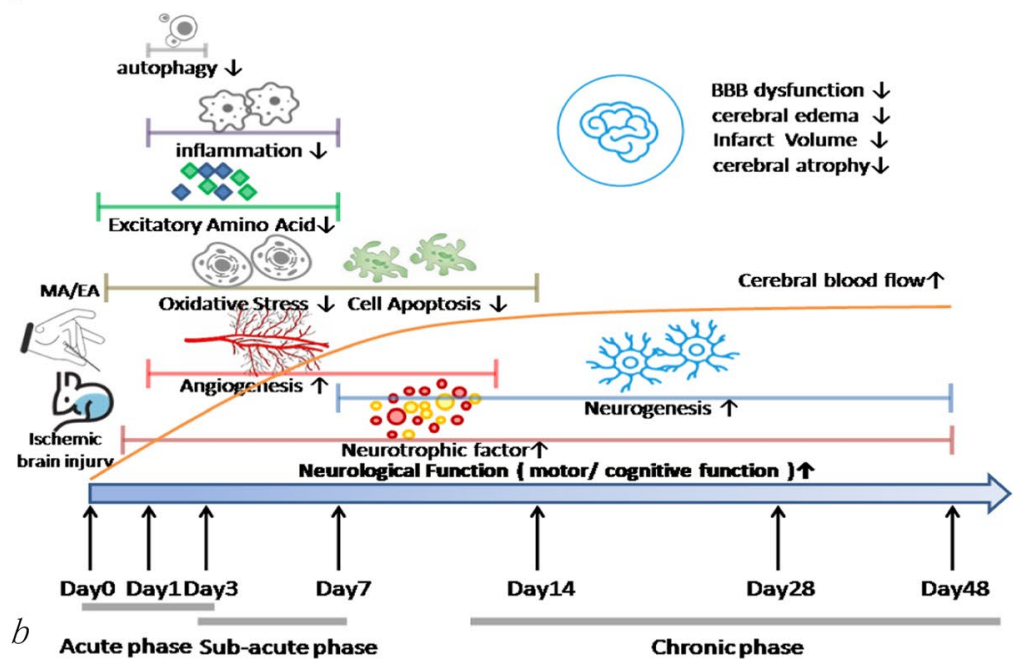

Fig. 2 (See legend on previous page.) 


\section{Vascular remodeling and angiogenesis Modulating integrity of the BBB}

Existing evidence indicates acupuncture might alleviate $\mathrm{BBB}$ dysfunction during ischemic stroke. During the acute stage of ischemic stroke, EA or MA could reduce $\mathrm{BBB}$ permeability and brain edema by increasing the expression of tight junction proteins $\mathrm{ZO}-1$ and claudin-5 in the ischemic cortex, decreasing the expression of ROS generation, NADPH oxidase 4 (NOX4) and astrocytic aquaporin 4 (AQP4) in the peri-infarct area [100], and inhibiting expression of MMP-2 and MMP-9, AQP4 and APQ9, which are implicated in BBB permeabilization and destruction [101, 102].

\section{Adjusting the CBF}

Ischemic stroke results from the occlusion of a cerebral artery followed by severe disturbances in blood supply through micro-vessels to brain tissues. Acupuncture has been shown to increase CBF and improve microcirculation, which could potentially explain the beneficial effects of acupuncture on treating cerebral ischemia. EA may reduce vasoconstriction and improve blood supply in ischemic region by suppressing the expression of Angiotensin II and its receptor-mediated signaling pathway [103], and induce changes in cell proliferation-associated miRNA expression after stroke [104].

\section{Promoting post-stroke angiogenesis.}

EA increase the endothelial cell proliferation from as early as $12 \mathrm{~h}$ post-MCAO [105]. Meanwhile, EA intervention can alleviate the injury of microvascular ultrastructure of focal ischemic cerebral tissues and upregulate cerebral VEGF mRNA expression, suggesting a role of EA in protecting ischemic brain tissues by facilitating the angiogenesis of capillary vessels and thereby restoring the function of the damaged microvasculature [106]. EA also accelerates and promotes production of stromal cell-derived factor-1 (SDF-1) which further induces the mobilization of EPCs [107], and increases the level of angiogenesis promoting factors in MCAO rats, including bFGF, angiogenin (Ang)-1/2, PDGF-b, which promote vascular endothelial cell proliferation and the recovery of neurological function [108]. Furthermore, EA at GV26 promotes regional CBF on the infarcted and noninfarcted hemisphere and increases the number of blood vessels in areas of infarctions by upregulating von Willebrand factor and vascular endothelial cell proliferation [109].

\section{Neurogenesis}

Acupuncture is potentially beneficial for post-stroke rehabilitation and is considered a promising preventive strategy for stroke. EA pretreatment or treatment after ischemic stroke generates neuroprotective and neuroregenerative effects [110]. A systematic review showed that acupuncture enhanced endogenous neurogenesis including proliferation, migration, and differentiation of NSCs in experimental ischemic stroke models [111]. Different stimulation methods of acupuncture as well as the selection of acupoints lead to neurogenesis in different regions of the brain. EA treatment applied at GV20 and GV14 after MCAO may promote functional recovery by enhancement of proliferation and differentiation of NSCs in the hippocampus and SVZ of the ipsilateral hemisphere via the BDNF and VEGF signaling pathway [112]. Acupuncture stimulation on GV26 enhanced the "selfrepairing" capacity of MCAO rats and alleviated neural functional damage by increasing the brain blood flow and the population of BrdU+, Nestin+, BrdU/nestin colabeled immunofluorescence positive cells in penumbra and promoting the expression of nestin mRNA in cortex and hippocampus, which facilitates endogenous neurogenesis and may be associated with regulating GSK-3 $\beta$ and PP2A expression [113].

\section{Influencing factors and limitations of acupuncture}

The National Institute of Health published a consensus statement that acupuncture may be useful as an adjunct treatment or an acceptable alternative to be included in a comprehensive management program for stroke care [114]. In recent years, clinical trials of acupuncture registered and carried out worldwide involve the evaluation of limb motor function, limb spasm and pain, swallowing function, activities of daily living, quality of life, cognitive function, depression, and anxiety state, etc., both in acute and recovery phase of ischemic stroke. Among them, two multicenter clinical trials showed that acupuncture was safe for the acute and subacute phase of ischemic stroke, reducing long-term mortality or disability rate and improving the neurologic deficits of patients $[115,116]$.

Shown from the available evidence, acupuncture plays varying roles in stroke treatment depending on the degree of cerebral ischemia. The efficacy is depending on the selection of acupoints and formula as well as the operator's manipulation skills, the timing of intervention, and the frequency of acupuncture sessions [117]. A multicenter prospective cohort study showed that early intervention produced better effects on the disability and motor dysfunction of patients with cerebral infarction and limb dysfunction [117]. However, more high-quality clinical evidence is still needed to build the consensus on the frequency and interval of acupuncture intervention in different phases of ischemic stroke.

Diversified acupoint selection, prescription, and stimulation parameters in the acupuncture treatment plan are some of the major barriers between laboratory research 
and clinical applications of acupuncture. The therapeutic mechanism of acupuncture on focal cerebral ischemia involves multiple targets and signaling pathways to exert acupuncture's neural protective effects, and this complexity increases the difficulty of setting up negative and placebo control groups. Lack of positive control and direct efficacy indices (such as infarct volume) also influence the evaluation of acupuncture efficacy. To obtain more reliable clinical effects, quantitative and standardized managing acupuncture treatment is necessary to be established based on the clarification of the 'acupuncture method-neural electrical signal code-acupuncture effect', and the 'dose-effect' relationship.

Although the simple operation and no facility-dependent properties are the advantages of acupuncture, acupuncture may has limited potential for sustainable technical improvement as a thousand-year-old welldeveloped clinical treatment method. Only a theoretical breakthrough based on modern biomedical analysis can optimize the current therapy protocols or the developement of a joint therapeutic methodology could significantly benefit the patients.

\section{Combination of stem cell therapy and acupuncture}

Stem cell transplantation and acupuncture are two individual types of multi-targeted therapies for ischemic stroke patients via different mechanisms and pathways. Acupuncture mainly modulates the microenvironment and activates endogenous restoration activities, while implantation of stem cells exerts its effect via exogenous stimulation of cell activities and/or direct integration for neuro-regeneration. Preclinical studies provided evidence that the combined stem cell transplantation and acupuncture treatment can significantly improve the neurological outcomes compared to a single type of therapy through three interactive mechanisms: (1) compensatory effects, where acupuncture increases the survival rate, migration, and homing ability of implanted cells; (2) enhancing effects that modulate the inflammatory response and oxidative stress; (3) synergistic effects that increase the regeneration ability of endogenous and exogenous NSCs $[118,119]$ (Fig. 3).

Compensatory effects-Stem cells facilitate the recovery and reconstruction of neurovascular unit and networks, as well as support the proliferation of endogenously activated NSC populations. Acupuncture can maintain normal stem cell functions and stimulate their

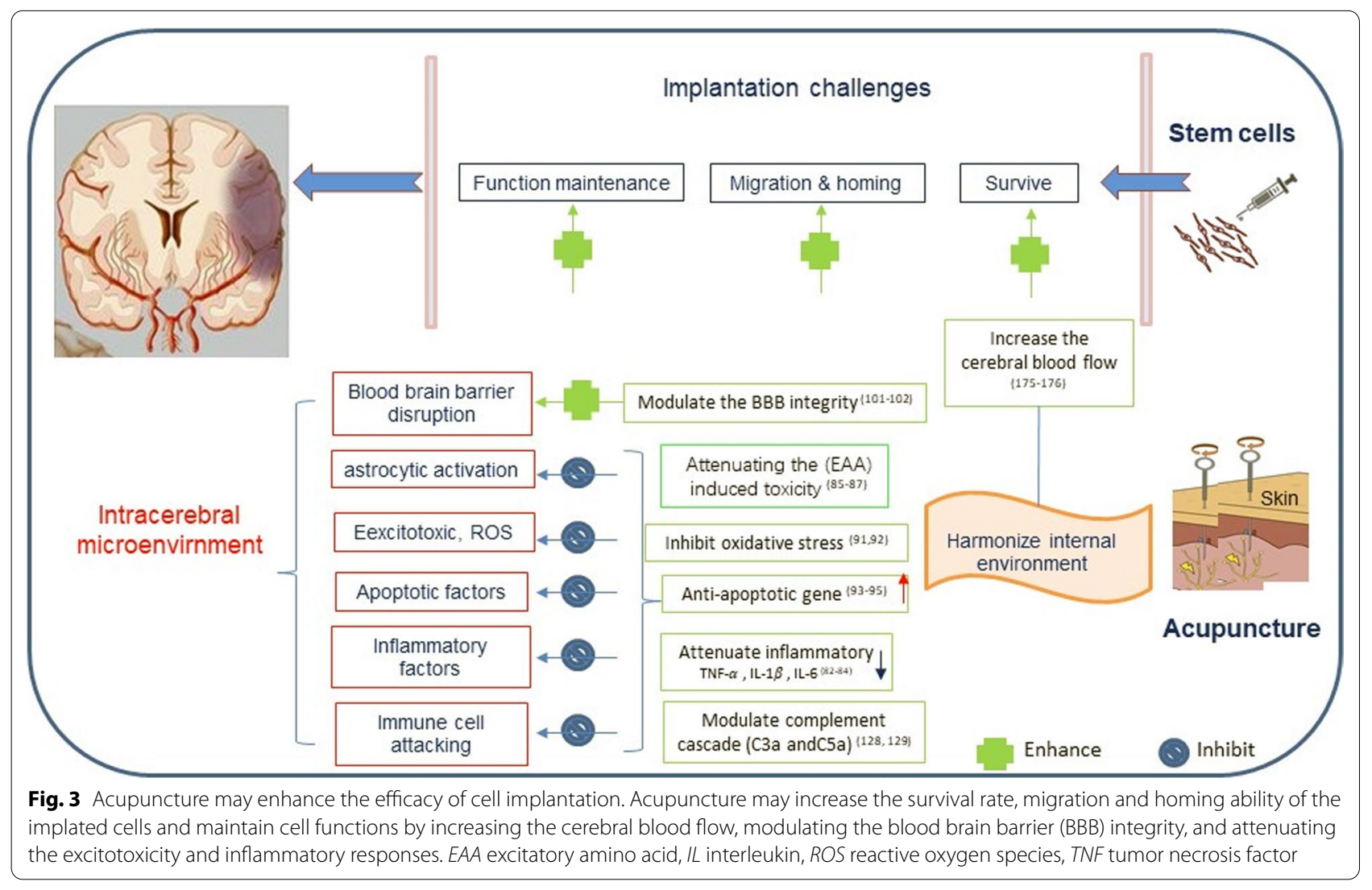


participation in neural regeneration by increasing cerebral blood flow and regulating chemokines and various cell signal transduction pathways.

Local microenvironment and immune responses are the decisive factors affecting the in vivo fate and function of implanted stem cells. The chemokines and cytokines secreted locally in infarct site, such as SDF-1, SCF, and VEGF, can not only promote the mobilization and homing of implanted cells to the lesions because of stem cells' chemotaxis characteristics, but also influence the damaged sites by recruiting the exogenous stem/progenitor cells and affecting their functions [120]. Our previous studies have found that acupuncture rebuilds or repairs the signal network by regulating the expression of stem cell microenvironment-related cytokines, which aid in maintaining the interaction and signal connection between transplanted stem cells and neighboring cells, therefore, promoteing the survival and proliferation of homed stem cells in the impaired brain tissue [119].

Passive entrapment in the microvascular system is one of the major stem cell physical localization mechanisms [228, 229]. Migrating and homing ability of implanted stem cells have been linked with the improved local blood flow (physical and physiological influences) and the administration of relative homing factors (biochemical influences) by numerous studies [121-123]. Both animal and clinical studies have proved that acupuncture can increase the cerebral blood flow and cerebral microcirculation by regulating the expression of angiogenesis-related factors, which result in a more conducive microenvironment for the survival of transplanted stem cells and the regeneration of NVUs at the infarct site [103].

Enhancing effect-Stem cells produce neurotrophic and immunoregulatory factors via paracrine mechanisms, which could potentially enhance the neuroprotective effect of acupuncture. However, the low homing efficiency and survival rate of the systemic administrated stem cells limit their therapeutic efficacy in ischemic stroke treatment. Although the stereotaxic implanted NSCs have displayed a better survival rate, they showed very limited therapeutic effects because there is no stroma reserved in the liquefactive necrosis lesion site $[124,125]$. Acupuncture can modulate the brain microenvironment and reduce the cell loss caused by excitotoxicity and oxidative stress, which could further enhance cell therapy efficiency.

Both stem cell transplantation and acupuncture displayed immunoregulatory and antioxidative stress ability through different mechanisms. In an endometrial injury animal study, Xia, et al. reported that EA elevated the expression of endometrial surface chemokine, activated the SDF-1/CXCR4 axis, which resulted in enhanced migration and paracrine effects of BMSCs. Improved histological outcome, vibrant cell activity, and increased cytokine level were detected within the endometrial damaged area, resulting in a better embryo implantation rate [126].

The complement system is able to modulate the inflammation and immune responses, which hae been found indirectly influencing the cytotherapy outcomes [127]. The anaphylatoxins $\mathrm{C} 3 \mathrm{a}$ and $\mathrm{C} 5 \mathrm{a}$, which are produced by complement components $\mathrm{C} 3$ and $\mathrm{C} 5$, are the human MSC chemo-attractants that direct the cell migrating and homing to the injured site when their $\mathrm{C} 3 \mathrm{a}$ and $\mathrm{C} 5 \mathrm{a}$ receptors $(\mathrm{C} 3 \mathrm{aR}$ and $\mathrm{C} 5 \mathrm{aR})$ coupled to the $\mathrm{MSC}_{\mathrm{1}}$-protein. The resilience of the implanted MSCs to oxidative stress and ROS is enhanced by C3aR and C5aR binging, which results in an increased survival rate and normal cellular functions maintenance [128]. Chen, et al. reported that acupuncture downregulated the pro-inflammatory cytokine TNF- $\alpha$ and IL- $1 \beta$, stimulated the release of complements, such as $\mathrm{C} 3 \mathrm{a}$ and $\mathrm{C} 5 \mathrm{a}$, as well as the secretion of cytokines SDF- 1 and TGF $\beta-1$, which played a synergistic immunomodulatory effects when combined with stem cell-seeded cryogel/hydrogel biomaterials for treating the diabetic skin wounds [129].

Synergistic effect-Acupuncture can activate a limited number of endogenous NSCs while intracerebral transplanted NSCs are able to differentiate into several types of neural cells directly involved in functional recovery of the damaged brain tissues.

The combined intervention of EA and HUCB-MSC transplantation showed a synergetic effect on upregulating VEGF expression and inhibited the cellular apoptosis in the cerebral ischemic penumbra of the ischemic infarct core $[130,131]$. Furthermore, Kim, et al. reported that elevated autologous NSC proliferation, BDNF, and neurotrophin-4 expression, and higher activation of the transcription factor cAMP response element-binding protein are detected in the brain of the combination therapy group in MCAO mice, indicating the combination therapy has more capability in neurotrophic factor modulation (Table 2). Combination therapy has been proved to be more advantageous than simple cell transplantation because it has a synergistic effect in co-regulating neurotrophic factors in the brain, promoting angiogenesis, inhibiting cell apoptosis, and promoting nerve function recovery of cerebral ischemia rats.

A later study from the same research group found that stereotactic injection of BDNF/NT4 receptor tropomyosin receptor kinase $\mathrm{B}$ (TrkB) gene-transfected BM-MSCs (TrkB-MSCs) combined with EA treatment in MCAO mice showed better motor function improvement than the single therapy. The histological analysis revealed that the combined therapy group resulted in 
Table 2 The combination of cytotherapy and acupuncture in cerebral ischemia treatment

\begin{tabular}{|c|c|c|c|c|c|}
\hline References & $\begin{array}{l}\text { Cytotherapy and } \\
\text { acupuncture } \\
\text { intervention }\end{array}$ & Control group & Effect index & $\begin{array}{l}\text { Comparison of effects between } \\
\text { groups }\end{array}$ & Mechanism index \\
\hline$[130]$ & $\begin{array}{l}\text { HUCB-MSCs } \\
\left(1 \times 10^{6} / 10 \mu \text { l, intrac- }\right. \\
\text { ranial transplanta- } \\
\text { tion); EA (GV26, GV20, } \\
\text { GV14, CV24, CV4, CV6; } \\
30 / 100 \mathrm{~Hz} / 5 \mathrm{~V} ; 20 \text { min; } \\
7,14,28 \text { days) }\end{array}$ & PBS group & $\begin{array}{l}\text { Modified neurological } \\
\text { severity score }\end{array}$ & $\mathrm{EA}+\mathrm{HUCB}-\mathrm{MSC}$ S $>$ HUCB-MSCs $>$ PBS & VEGF-positive cells $\uparrow$ \\
\hline [131] & $\begin{array}{l}\text { HUCB-MSCs } \\
\left(1 \times 10^{6} / 10 \mu \text { l, intrac- }\right. \\
\text { ranial transplanta- } \\
\text { tion); EA (GV26, GV20, } \\
\text { GV14, CV24, CV4, CV6; } \\
30 / 100 \mathrm{~Hz} / 5 V ; 20 \text { min; } \\
7,14,28 \text { days) }\end{array}$ & PBS group & Pathological lesion & $E A+H U C B-M S C s>H U C B-M S C s>P B S$ & Cellular apoptosis $\downarrow$ \\
\hline$[118]$ & $\begin{array}{l}\text { mBMSC }\left(1 \times 10^{5} / 5 \mu \mathrm{l}\right. \\
\text { intracranial trans- } \\
\text { plantation); EA (GV14, } \\
\mathrm{GV} 20,2 \mathrm{~Hz} / 2 \mathrm{~V} ; 20 \mathrm{~min} ; \\
12 \text { days) }\end{array}$ & MCAO group & $\begin{array}{l}\text { Motor and cognitive } \\
\text { dysfunctions } \\
\text { Atrophic volume }\end{array}$ & $\mathrm{mBMSC}+\mathrm{EA}>\mathrm{EA}>\mathrm{mBMSC}>\mathrm{MCAO}$ & $\begin{array}{l}\text { mBDNF } \uparrow, N T 4 \uparrow \\
\text { CAMP } \uparrow, p C R E B \uparrow \\
\text { Proliferation of neural } \\
\text { progenitor cells } \uparrow\end{array}$ \\
\hline [132] & $\begin{array}{l}\text { TrkB-MSCs } \\
\left(1 \times 10^{6} / 2 \mu \text { l, intrac- }\right. \\
\text { ranial transplanta- } \\
\text { tion); EA (GV14, GV20, } \\
2 \mathrm{~Hz} / 2 \mathrm{~V} ; 20 \text { min; } \\
10-22 \text { days) }\end{array}$ & $\begin{array}{l}\text { PBS group, MSCs } \\
\text { group, MSCs + EA } \\
\text { group }\end{array}$ & $\begin{array}{l}\text { Motor and cognitive } \\
\text { function }\end{array}$ & $\begin{array}{l}\text { TrkB-MSCs + EA }>\text { TrkB- } \\
M S C s>M S C s+E A>M S C s>P B S\end{array}$ & $\begin{array}{l}\text { BDNF } \uparrow, N T 4 \uparrow \\
\text { Survival, differentia- } \\
\text { tion and migration of } \\
\text { TrkB-MSCs into mature } \\
\text { neuronal cells } \uparrow \\
\text { Activation of BDNF/NT4/ } \\
\text { TrkB Signaling pathway }\end{array}$ \\
\hline
\end{tabular}

more TrkB-MSCs differentiating into neural cells, which suggests EA displayed an enhancing role in the composition therapy by increasing the expression of neurotrophic factors, BDNF and NT4, to activate the residential NSCs as well as to promote the differentiation of TrkB-MSCs into matured neurons [118, 132].

\section{Conclusion and prospects}

Preclinical and clinical study revealed that both stem cell transplantation and acupuncture can improve the recovery and rehabilitation of ischemic stroke to a certain extent and acquire multi-target advantages compared to the currently available clinical treatments. A combined therapy may increase the implanted stem cells' survival, homing, and functional differentiation rate, and benefit ischemic stroke patients by enhancing and synergizing the effects of individual treatments and compensating for the deficits of each therapy compared to when each therapy is administered on its own (Fig. 4). 


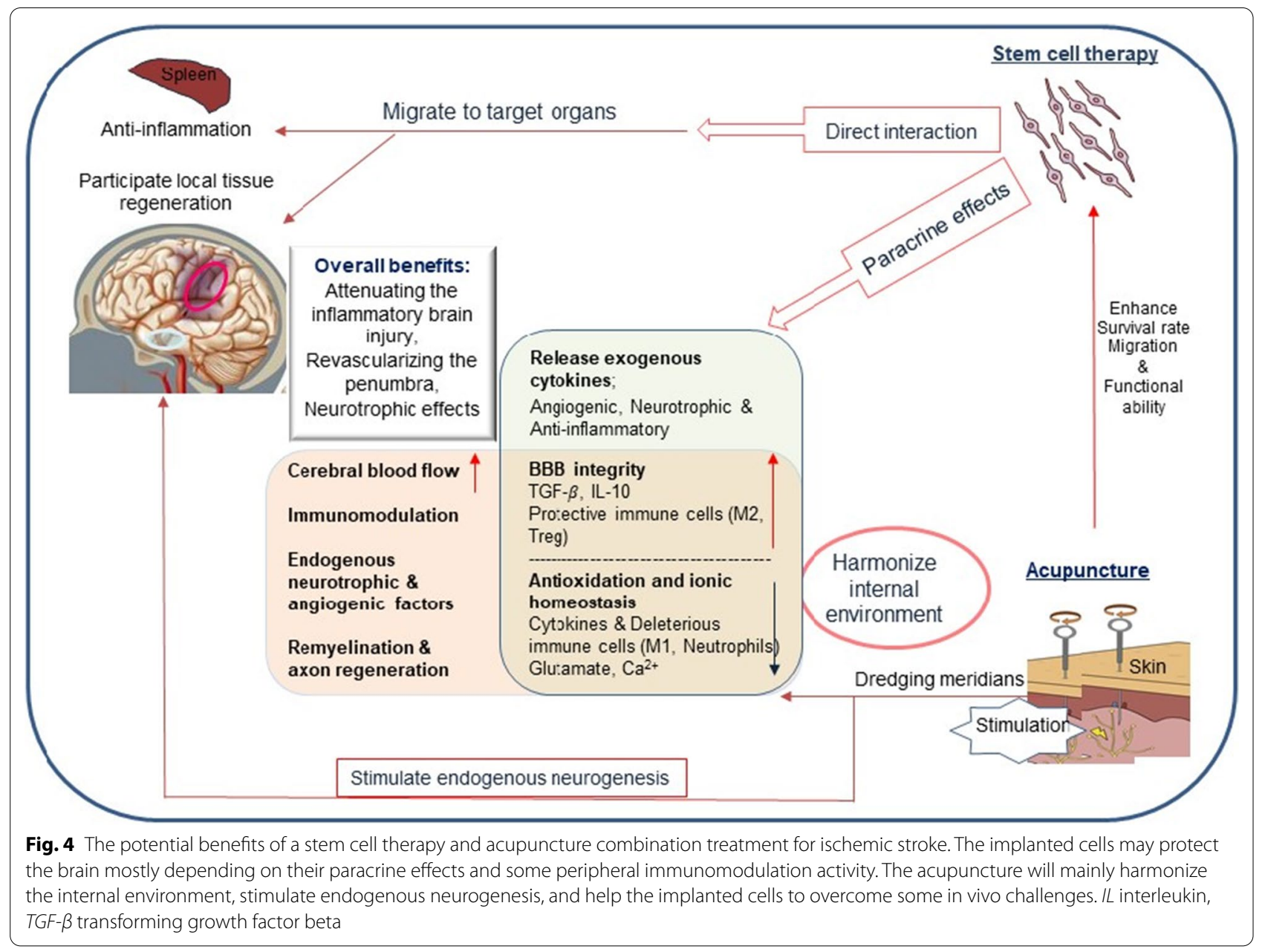

\section{Prospects}

Stem cell therapy offers more dynamic interventions compared to drugs. The convenient, low-cost, and safe acupuncture treatment is an ideal supplementary therapy for stem cell therapy in ischemic stroke management. On the premise of quantified acupuncture methodology, the benefits of combined therapy should be evaluated by randomized, double-blind clinical trials that group ischemic stroke patients by age, obstruction location, primary cause, and stage to narrow down and examine specific indications. Novel molecular biological detections, cell labeling, and imaging techniques should be able to disclose more neuroprotection, neuro-regeneration, and anti-inflammatory solution as well as other mechanisms of stroke therapies.

\section{Abbreviations}

Ang: Angiogenin; AlF: Apoptosis-inducing factor; FGF-2: Basic fibroblast growth factor; BCI-2: B cell lymphoma 2; BBB: Blood-brain barrier; BMP: Bone morphogenetic protein; BDNF: Brain-derived neurotrophic factor; ERK/JNK/ p38: C-Jun N-terminal kinase (JNK)/p38; CNS: Central nervous system; CBF: Cerebral Blood Flow; RCTs: Controlled trials; EA: Electrical acupuncture; EAA: Excitatory amino acid; ESCs: Embryonic stem cells; ENOS: Endothelial nitric oxide synthase; EPCs: Endothelial progenitor cells; EGF: Epidermal growth factor; EPO: Erythropoietin; ERK: Extracellular signal-regulated kinase; GDNF: Glial-derived neurotrophic factor; GFAP: Glial fibrillary acidic protein; HSCs: Hematological stem cells; HSPGs: Heparan sulfate proteoglycans; 4-OHT: 4-Hydroxytamoxifen; iPSCs: Induced pluripotent stem cells; IKB: Inhibitor of NF-KB; IL: Interleukin; IA: Intraarterial; IT: Intrathecal; IP: Intraperitoneal; IV: Intravenous; Jag1: Jagged-1; LPS: Lipopolysaccharide; Mtor: Mammalian target of rapamycin; MA: Manual acupuncture; mmps: Matrix metalloproteinases; mscs: Mesenchymal stem cells or multipotent stem cells; MCAO: Middle cerebral artery occlusion; mncs: Mononuclear cells; NK: Natural killer cells; NGF: Nerve growth factor; npcs: Neural progenitor/precursor cells; NRG: Neural regeneration; nscs: Neural stem cells; neun: Neuronal nuclei; NO: Nitric oxide; NMDA: N-Methyl-D-aspartate; (ngr)/rhoa: Nogo-A/Nogo receptor; DII4: Notch-ligands Delta-4; Olig-2: Oligodendrocyte; OGD: Oxygen-glucose deprivation; PDGF: Platelet-derived growth factor; PE: Paracrine effect; pbmcs: Peripheral blood mononuclear cells; PI3K/Akt: Phosphatidylinositol 3-kinase/protein kinase B; 
ROS: Reactive oxygen species; rcts: Randomized controlled trials; Tregs: Regulatory T cells; ROCK: Rho-associated protein kinase; SVZ: Subventricular zone; SGZ: Sub-granular zone; SHH: Sonic hedgehog; SDF-1 a: Stromal cell-derived factor-1a; TCM: Traditional Chinese Medicine; TGF- $\beta$ : Transforming growth factor beta; TREM2: Triggering receptor expressed on myeloid cells 2; TNF: Tumor necrosis factor; UCB: Umbilical cord blood; VEGF: Vascular endothelial growth factor; XNKQ: XingNaoKaiQiao.

\section{Supplementary Information}

The online version contains supplementary material available at https://doi. org/10.1186/s13287-022-02761-y.

Additional file 1. Supplementary Table 1. Supplementary Table 2.

\section{Acknowledgements}

The authors wish to thank Dr. Casey Adam for her thoughtful feedback on the manuscript.

\section{Authors' contributions}

$H J, J H, X Z, Y D, X S$, and $H Y$ designed the study. $H J, J H, C H, X Z$, and LZ wrote the manuscript. $\mathrm{HY}, \mathrm{LH}$, and $\mathrm{ZC}$ reviewed and/or edited the manuscript. All authors read and approved the final manuscript.

\section{Funding}

This project is supported by funding from the Biotechnology and Biological Sciences Research Council (BB/H008527/1), UK, National Key Research and Development Program of China (2019YFC0840709), National Natural Science Foundation of China (82074533), Science and Technology Program of Tianjin (18PLTCSY00060, 18PTLCSY00050), Tianjin Natural Science Foundation (18JCYBJC92300), and Scientific Research Project of Tianjin Education Commission (2017KJ145).

\section{Availability of data and materials}

Not applicable.

\section{Declarations}

Ethics approval and consent to participate

Not applicable.

\section{Consent for publication}

Not applicable.

\section{Competing interests}

The authors declare that they have no competing interests.

\section{Author details}

${ }^{1}$ The Oxford Suzhou Centre for Advanced Research (OSCAR), Building A, 388 Ruo Shui Road, Suzhou Industrial Park, Jiangsu, People's Republic of China. ${ }^{2}$ First Teaching Hospital of Tianjin University of Traditional Chinese Medicine, 88 Chang Ling Road, Xi Qing District, Tianjin, People's Republic of China. ${ }^{3}$ National Clinical Research Center for Chinese Medicine Acupuncture and Moxibustion, 88 Chang Ling Road, Xi Qing District, Tianjin, People's Republic of China. ${ }^{4}$ Department of Engineering Science, Institute of Biomedical Engineering, University of Oxford, Roosevelt Drive, Oxford OX3 7DQ, UK.

Received: 16 September 2021 Accepted: 17 January 2022

Published online: 03 March 2022

\section{References}

1. Collaborators GBDS. Global, regional, and national burden of stroke, 1990-2016: a systematic analysis for the Global Burden of Disease Study 2016. Lancet Neurol. 2019;18(5):439-58.
2. Writing Group M, Mozaffarian D, Benjamin EJ, Go AS, Arnett DK, Blaha MJ, et al. Heart disease and stroke statistics-2016 update: a report from the American Heart Association. Circulation. 2016;133(4):e38-360.

3. Selway LD. State of the science: hypoxic ischemic encephalopathy and hypothermic intervention for neonates. Adv Neonatal Care. 2010;10(2):60-6 (quiz 7-8).

4. Benjamin EJ, Virani SS, Callaway CW, Chamberlain AM, Chang AR, Cheng S, et al. Heart disease and stroke statistics-2018 update: a report from the American Heart Association. Circulation. 2018;137(12):e67-492.

5. Ana-Maria B, Carmen A, Valerica T. Current stage and future perspective of stem cell therapy in ischemic stroke. J Stem Cell Res Ther. 2017;7(3):1-7.

6. Brott T, Bogousslavsky J. Treatment of acute ischemic stroke. N Engl J Med. 2000;343(10):710-22.

7. Powers WJ, Rabinstein AA, Ackerson T, Adeoye OM, Bambakidis NC, Becker K, et al. Guidelines for the early management of patients with acute ischemic stroke: 2019 update to the 2018 guidelines for the early management of acute ischemic stroke: a guideline for healthcare professionals from the American Heart Association/American Stroke Association. Stroke. 2019:50(12):e344-418.

8. Azzopardi D, Strohm B, Marlow N, Brocklehurst P, Deierl A, Eddama $\mathrm{O}$, et al. Effects of hypothermia for perinatal asphyxia on childhood outcomes. N Engl J Med. 2014;371(2):140-9.

9. Ploughman M, Windle V, MacLellan CL, White N, Doré JJ, Corbett D. Brain-derived neurotrophic factor contributes to recovery of skilled reaching after focal ischemia in rats. Stroke. 2009;40(4):1490-5.

10. Souvenir R, Doycheva D, Zhang JH, Tang J. Erythropoietin in stroke therapy: friend or foe. Curr Med Chem. 2015;22(10):1205-13.

11. Arvidsson A, Collin T, Kirik D, Kokaia Z, Lindvall O. Neuronal replacement from endogenous precursors in the adult brain after stroke. Nat Med. 2002:8(9):963-70.

12. Bhasin A, Srivastava MVP, Kumaran SS, Mohanty S, Bhatia R, Bose S, et al. Autologous mesenchymal stem cells in chronic stroke. Cerebrovasc Dis Extra. 2011;1(1):93-104.

13. Dai J, Li S-Q, Qiu Y-M, Xiong W-H, Yin Y-H, Jia F, et al. Migration of neural stem cells to ischemic brain regions in ischemic stroke in rats. Neurosci Lett. 2013;552:124-8.

14. Shin S, Yang SP, Yu A, Yoo J, Lim SM, Lee E. Effectiveness and safety of electroacupuncture for poststroke patients with shoulder pain: study protocol for a double-center, randomized, patient- and assessorblinded, sham-controlled, parallel, clinical trial. BMC Complement Altern Med. 2019;19(1):58

15. Zhang B, Han Y, Huang X, Liu Z, Li S, Chang J, et al. Acupuncture is effective in improving functional communication in post-stroke aphasia: a systematic review and meta-analysis of randomized controlled trials. Wien Klin Wochenschr. 2019;131(9-10):221-32.

16. Zhang CH, Bian JL, Meng ZH, Meng LN, Ren XS, Wang ZL, et al. Tongguan Liqiao acupuncture therapy improves dysphagia after brainstem stroke. Neural Regen Res. 2016;11(2):285-91.

17. Zhang XY, Li YX, Liu DL, Zhang BY, Chen DM. The effectiveness of acupuncture therapy in patients with post-stroke depression: an updated meta-analysis of randomized controlled trials. Medicine (Baltimore). 2019;98(22):e15894.

18. Yang A, Wu HM, Tang JL, Xu L, Yang M, Liu GJ. Acupuncture for stroke rehabilitation. Cochrane Database Syst Rev. 2016;2016(8):CD004131.

19. Xu M, Li D, Zhang S. Acupuncture for acute stroke. Cochrane Database Syst Rev. 2018;3:CD003317.

20. Hao L, Zou Z, Tian H, Zhang Y, Zhou H, Liu L. Stem cell-based therapies for ischemic stroke. Biomed Res Int. 2014;2014:468748.

21. Tang Y, Yu P, Cheng L. Current progress in the derivation and therapeutic application of neural stem cells. Cell Death Dis. 2017;8(10):e3108-e.

22. Banda E, Grabel L. Directed differentiation of human embryonic stem cells into neural progenitors. Methods Mol Biol. 2016;1307:289-98.

23. Emdad L, D'Souza SL, Kothari HP, Qadeer ZA, Germano IM. Efficient differentiation of human embryonic and induced pluripotent stem cells into functional astrocytes. Stem Cells Dev. 2012;21(3):404-10.

24. Liu J. Induced pluripotent stem cell-derived neural stem cells: new hope for stroke? Stem Cell Res Ther. 2013;4(5):115.

25. Swistowski A, Peng J, Liu Q, Mali P, Rao MS, Cheng L, et al. Efficient generation of functional dopaminergic neurons from human 
induced pluripotent stem cells under defined conditions. Stem Cells. 2010;28(10):1893-904.

26. Shi YC, Kirwan P, Livesey FJ. Directed differentiation of human pluripotent stem cells to cerebral cortex neurons and neural networks. Nat Protoc. 2012;7(10):1836-46.

27. Willerth SM. Neural tissue engineering using embryonic and induced pluripotent stem cells. Stem Cell Res Ther. 2011;2:17.

28. Zheng WM, Zhuge QC, Zhong M, Chen GR, Shao B, Wang H, et al. Neurogenesis in adult human brain after traumatic brain injury. J Neurotraum. 2013;30(22):1872-80.

29. Wen Y, Jin S. Production of neural stem cells from human pluripotent stem cells. J Biotechnol. 2014;188:122-9.

30. Harris VK, Stark J, Vyshkina T, Blackshear L, Joo G, Stefanova V, et al. Phase I trial of intrathecal mesenchymal stem cell-derived neural progenitors in progressive multiple sclerosis. EBioMedicine. 2018;29:23-30.

31. Mezey E, Key S, Vogelsang G, Szalayova I, Lange GD, Crain B. Transplanted bone marrow generates new neurons in human brains. Proc Natl Acad Sci USA. 2003;100(3):1364-9.

32. Kalladka D, Sinden J, Pollock K, Haig C, McLean J, Smith W, et al. Human neural stem cells in patients with chronic ischaemic stroke (PISCES): a phase 1, first-in-man study. Lancet. 2016;388(10046):787-96.

33. Sinden JD, Hicks C, Stroemer P, Vishnubhatla I, Corteling R. Human neural stem cell therapy for chronic ischemic stroke: charting progress from laboratory to patients. Stem Cells Dev. 2017:26(13):933-47.

34. Hass R, Kasper C, Böhm S, Jacobs R. Different populations and sources of human mesenchymal stem cells (MSC): a comparison of adult and neonatal tissue-derived MSC. Cell Commun Signal. 2011;9:12.

35. Ding DC, Shyu WC, Chiang MF, Lin SZ, Chang YC, Wang HJ, et al. Enhancement of neuroplasticity through upregulation of beta1integrin in human umbilical cord-derived stromal cell implanted stroke model. Neurobiol Dis. 2007;27(3):339-53

36. Si J-W, Wang X-D, Shen SG. Perinatal stem cells: a promising cell resource for tissue engineering of craniofacial bone. World I Stem Cells. 2015;7(1):149-59.

37. Huang L, Liu Y, Lu J, Cerqueira B, Misra V, Duong TQ. Intraarterial transplantation of human umbilical cord blood mononuclear cells in hyperacute stroke improves vascular function. Stem Cell Res Ther. 2017;8(1):74.

38. Chen J, Sanberg PR, Li Y, Wang L, Lu M, Willing AE, et al. Intravenous administration of human umbilical cord blood reduces behavioral deficits after stroke in rats. Stroke. 2001;32(11):2682-8.

39. Rosenkranz K, Meier C. Umbilical cord blood cell transplantation after brain ischemia-from recovery of function to cellular mechanisms. Ann Anat. 2011;193(4):371-9.

40. Wan B, Pan X, Ma J, Luo Y, Liu J, Zhao G. Umbilical cord blood troponin I, myoglobin and CK-MB in neonatal hypoxic ischemic encephalopathy and the clinical significance. Exp Ther Med. 2020;19(1):545-50.

41. Zhao C, Zhang P, Cheng G. Umbilical cord blood transplantation for neonatal hypoxic-ischemic encephalopathy. Zhonghua Er Ke Za Zhi. 2015;53(5):390-3

42. Liao S, Luo C, Cao B, Hu H, Wang S, Yue H, et al. Endothelial progenitor cells for ischemic stroke: update on basic research and application. Stem Cells Int. 2017;2017:2193432.

43. Fang J, Guo Y, Tan S, Li Z, Xie H, Chen P, et al. Autologous endothelial progenitor cells transplantation for acute ischemic stroke: a 4-year follow-up study. Stem Cells Transl Med. 2019;8(1):14-21.

44. Rosová I, Dao M, Capoccia B, Link D, Nolta JA. Hypoxic preconditioning results in increased motility and improved therapeutic potential of human mesenchymal stem cells. Stem Cells. 2008;26(8):2173-82.

45. Kaneko Y, Tajiri N, Su TP, Wang Y, Borlongan CV. Combination treatment of hypothermia and mesenchymal stromal cells amplifies neuroprotection in primary rat neurons exposed to hypoxic-ischemic-like injury in vitro: role of the opioid system. PLoS ONE. 2012;7(10):e47583.

46. Baez-Jurado E, Guio-Vega G, Hidalgo-Lanussa O, González J, Echeverria $\checkmark$, Ashraf GM, et al. Mitochondrial neuroglobin is necessary for protection induced by conditioned medium from human adipose-derived mesenchymal stem cells in astrocytic cells subjected to scratch and metabolic injury. Mol Neurobiol. 2019;56(7):5167-87.

47. Wen C, Huang C, Yang M, Fan C, Li Q, Zhao J, et al. The secretion from bone marrow mesenchymal stem cells pretreated with berberine rescues neurons with oxidative damage through activation of the Keap1-Nrf2-HO-1 signaling pathway. Neurotox Res. 2020;38(1):59-73.
48. Lee HJ, Lee JK, Lee H, Shin JW, Carter JE, Sakamoto T, et al. The therapeutic potential of human umbilical cord blood-derived mesenchymal stem cells in Alzheimer's disease. Neurosci Lett. 2010:481(1):30-5.

49. Hayakawa K, Esposito E, Wang X, Terasaki Y, Liu Y, Xing C, et al. Transfer of mitochondria from astrocytes to neurons after stroke. Nature. 2016;535(7613):551-5

50. Boukelmoune N, Chiu GS, Kavelaars A, Heijnen CJ. Mitochondrial transfer from mesenchymal stem cells to neural stem cells protects against the neurotoxic effects of cisplatin. Acta Neuropathol Commun. 2018;6(1):139

51. Bernardo ME, Fibbe WE. Mesenchymal stromal cells: sensors and switchers of inflammation. Cell Stem Cell. 2013;13(4):392-402

52. Jiang $\mathrm{W}, \mathrm{Xu}$ J. Immune modulation by mesenchymal stem cells. Cell Prolif. 2020;53(1):e12712-e.

53. Prigione I, Benvenuto F, Bocca P, Battistini L, Uccelli A, Pistoia V. Reciprocal interactions between human mesenchymal stem cells and gammadelta T cells or invariant natural killer T cells. Stem Cells. 2009:27(3):693-702

54. Uccelli A, Moretta L, Pistoia V. Immunoregulatory function of mesenchymal stem cells. Eur J Immunol. 2006:36(10):2566-73.

55. Gelderblom M, Arunachalam P, Magnus T. $ү \delta$ T cells as early sensors of tissue damage and mediators of secondary neurodegeneration. Front Cell Neurosci. 2014;8:368.

56. Wang LQ, Lin ZZ, Zhang HX, Shao B, Xiao L, Jiang HG, et al. Timing and dose regimens of marrow mesenchymal stem cell transplantation affect the outcomes and neuroinflammatory response after ischemic stroke. CNS Neurosci Ther. 2014:20(4):317-26.

57. Prockop DJ. Concise review: two negative feedback loops place mesenchymal stem/stromal cells at the center of early regulators of inflammation. Stem Cells. 2013;31(10):2042-6.

58. Blanchette M, Daneman R. Formation and maintenance of the BBB. Mech Dev. 2015;138(Pt 1):8-16.

59. Abdullahi W, Tripathi D, Ronaldson PT. Blood-brain barrier dysfunction in ischemic stroke: targeting tight junctions and transporters for vascular protection. Am J Physiol Cell Physiol. 2018;315(3):C343-56.

60. Taguchi A, Soma T, Tanaka H, Kanda T, Nishimura H, Yoshikawa H, et al. Administration of $\mathrm{CD} 34+$ cells after stroke enhances neurogenesis via angiogenesis in a mouse model. J Clin Invest. 2004;114(3):330-8.

61. Cheng Z, Wang L, Qu M, Liang H, Li W, Li Y, et al. Mesenchymal stem cells attenuate blood-brain barrier leakage after cerebral ischemia in mice. J Neuroinflammation. 2018;15(1):135.

62. Tang G, Liu Y, Zhang Z, Lu Y, Wang Y, Huang J, et al. Mesenchymal stem cells maintain blood-brain barrier integrity by inhibiting aquaporin-4 upregulation after cerebral ischemia. Stem Cells. 2014;32(12):3150-62.

63. Marcola M, Rodrigues CE. Endothelial progenitor cells in tumor angiogenesis: another brick in the wall. Stem Cells Int. 2015;2015:832649.

64. Kinnaird T, Stabile E, Burnett MS, Lee CW, Barr S, Fuchs S, et al. Marrowderived stromal cells express genes encoding a broad spectrum of arteriogenic cytokines and promote in-vitro and in-vivo arteriogenesis through paracrine mechanisms (vol 94, pg 678, 2004). Circ Res. 2005:97(3):E51-E.

65. Kang TY, Bocci F, Jolly MK, Levin H, Onuchic JN, Levchenko A. Pericytes enable effective angiogenesis in the presence of proinflammatory signals. Proc Natl Acad Sci USA. 2019;116(47):23551-61.

66. Zhang JJ, Zhu JJ, Hu YB, Xiang GH, Deng LC, Wu FZ, et al. Transplantation of bFGF-expressing neural stem cells promotes cell migration and functional recovery in rat brain after transient ischemic stroke. Oncotarget. 2017:8(60):102067-77.

67. Kolios G, Moodley Y. Introduction to stem cells and regenerative medicine. Respiration. 2013;85(1):3-10.

68. Hu C, Li L. Preconditioning influences mesenchymal stem cell properties in vitro and in vivo. J Cell Mol Med. 2018;22(3):1428-42.

69. Muir KW, Bulters D, Willmot M, Sprigg N, Dixit A, Ward N, et al. Intracerebral implantation of human neural stem cells and motor recovery after stroke: multicentre prospective single-arm study (PISCES-2). J Neurol Neurosurg Psychiatry. 2020;91(4):396.

70. Sironi F, Vallarola A, Violatto MB, Talamini L, Freschi M, De Gioia R, et al. Multiple intracerebroventricular injections of human umbilical cord mesenchymal stem cells delay motor neurons loss but not disease progression of SOD1G93A mice. Stem Cell Res. 2017;25:166-78. 
71. Iwasa SN, Babona-Pilipos R, Morshead CM. Environmental factors that influence stem cell migration: an "electric field." Stem Cells Int. 2017:2017:4276927.

72. Sart S, Song L, Li Y. Controlling redox status for stem cell survival, expansion, and differentiation. Oxid Med Cell Longev. 2015;2015:105135.

73. Zhu W, Ye Y, Liu Y, Wang XR, Shi GX, Zhang S, et al. Mechanisms of acupuncture therapy for cerebral ischemia: an evidence-based review of clinical and animal studies on cerebral ischemia. J Neuroimmune Pharmacol. 2017;12(4):575-92

74. Peng L, Zhang C, Zhou L, Zuo HX, He XK, Niu YM. Traditional manual acupuncture combined with rehabilitation therapy for shoulder hand syndrome after stroke within the Chinese healthcare system: a systematic review and meta-analysis. Clin Rehabil. 2018;32(4):429-39.

75. Liu X, Zhang X, Nie K, Jia Y, Li J, Ling Z, et al. Effect of electro-scalp acupuncture on acute ischemic stroke: a randomized, single blind, trial. J Tradit Chin Med. 2018;38(1):95-100.

76. Shao Y, Wang P, Wang Q, Yu L, Zhang L, Wang W. Eye-acupuncture with rehabilitation therapy for stroke. Medicine (Baltimore). 2020;99(18):e20096

77. Yang ZX, Xie JH, Liu DD. Xingnao Kaiqiao needling method for acute ischemic stroke: a meta-analysis of safety and efficacy. Neural Regen Res. 2017;12(8):1308-14.

78. Xu J, Pei J, Fu QH, Wang LY, Zhan YJ, Tao L. Earlier acupuncture enhancing long-term effects on motor dysfunction in acute ischemic stroke: retrospective cohort study. Am J Chin Med. 2020:48(8):1787-802.

79. Chen L, Fang J, Ma R, Gu X, Chen L, Li J, et al. Additional effects of acupuncture on early comprehensive rehabilitation in patients with mild to moderate acute ischemic stroke: a multicenter randomized controlled trial. BMC Complement Altern Med. 2016;16:226.

80. Liu SY, Hsieh CL, Wei TS, Liu PT, Chang YJ, Li TC. Acupuncture stimulation improves balance function in stroke patients: a single-blinded controlled, randomized study. Am J Chin Med. 2009;37(3):483-94.

81. Chen J, Wang J, Huang Y, Lai X, Tang C, Yang J, et al. Modulatory effect of acupuncture at Waiguan (TE5) on the functional connectivity of the central nervous system of patients with ischemic stroke in the left basal ganglia. PLoS ONE. 2014;9(6):e96777.

82. Wang JH, Du XZ, Zhang TZ, Li XL, Zhao M, Bao YC, et al. Scalp-acupuncture improves neurological function by regulating expression of IL-10 mRNA, IL-6 mRNA and TNF-alpha of parahippocampal gyrus in cerebral ischemic rats. Zhen Ci Yan Jiu. 2019;44(3):183-8.

83. Wang JH, Zhang TZ, Zhao M, Bao YC, Yan Q, Zhang ZC, et al. Scalpacupuncture improves neurological function by regulating expression of NF-kappaB p 65 mRNA, IkappaB mRNA and IL-1 beta and TNF-alpha in parahippocampal gyrus of cerebral ischemia rats. Zhen Ci Yan Jiu. 2018;43(9):556-61.

84. Wang Q, Huang W, Wu HY. Acupuncture reduces acute cerebral ischemia by suppressing local and peripheral inflammation and regulating expression of cerebral protein silent information regulator factor 2-related enzyme 1 and nuclear factor-kappaB in rats. Zhen Ci Yan Jiu. 2018;43(3):146-51.

85. Zhang TS, Yang L, Hu R, Qiao XL, Yang X, Liu XG. Effect of electroacupuncture on the contents of excitatory amino acids in cerebral tissue at different time courses in rats with cerebral ischemia and reperfusion injury. Zhen Ci Yan Jiu. 2007;32(4):234-6.

86. Zhang Y, Mao X, Lin R, Li Z, Lin J. Electroacupuncture ameliorates cognitive impairment through inhibition of $\mathrm{Ca}(2+)$-mediated neurotoxicity in a rat model of cerebral ischaemia-reperfusion injury. Acupunct Med. 2018;36(6):401-7.

87. Liu Z, Chen X, Gao Y, Sun S, Yang L, Yang Q, et al. Involvement of GluR2 up-regulation in neuroprotection by electroacupuncture pretreatment via cannabinoid CB1 receptor in mice. Sci Rep. 2015;5:9490

88. Guo Z, Zhang L, Wu Y, Li M, Yang X, He Z, et al. The role of glutamate transporter- 1 in the acquisition of brain ischaemic tolerance in rats induced by electro-acupuncture pre-treatment. Brain Inj. 2015;29(3):396-402

89. Liu J, Wu YY, Yu XL, Jia HY, Mao QY, Fang JQ. Temporal effect of acupuncture on amino acid neurotransmitters in rats with acute cerebral ischaemia. Acupunct Med. 2019;37(4):252-8

90. Su XT, Wang L, Ma SM, Cao Y, Yang NN, Lin LL, et al. Mechanisms of acupuncture in the regulation of oxidative stress in treating ischemic stroke. Oxid Med Cell Longev. 2020;2020:7875396.
91. Su X, Wu Z, Mai F, Fan Z, Du S, Qian H, et al. 'Governor vessel-unblocking and mind-regulating' acupuncture therapy ameliorates cognitive dysfunction in a rat model of middle cerebral artery occlusion. Int J Mol Med. 2019;43(1):221-32.

92. Zhang $X$, Wu B, Nie K, Jia Y, Yu J. Effects of acupuncture on declined cerebral blood flow, impaired mitochondrial respiratory function and oxidative stress in multi-infarct dementia rats. Neurochem Int. 2014;65:23-9.

93. Xue $X$, You Y, Tao J, Ye X, Huang J, Yang S, et al. Electro-acupuncture at points of Zusanli and Quchi exerts anti-apoptotic effect through the modulation of PI3K/Akt signaling pathway. Neurosci Lett. 2014;558:14-9.

94. Xing Y, Yang SD, Wang MM, Dong F, Feng YS, Zhang F. Electroacupuncture alleviated neuronal apoptosis following ischemic stroke in rats via midkine and ERK/JNK/p38 signaling pathway. J Mol Neurosci. 2018;66(1):26-36

95. Liu F, Jiang YJ, Zhao HJ, Yao LQ, Chen LD. Electroacupuncture ameliorates cognitive impairment and regulates the expression of apoptosisrelated genes $\mathrm{BCl}-2$ and $\mathrm{Bax}$ in rats with cerebral ischaemia-reperfusion injury. Acupunct Med. 2015;33(6):478-84.

96. Zhang Y, Lan R, Wang J, Li XY, Zhu DN, Ma YZ, et al. Acupuncture reduced apoptosis and up-regulated BDNF and GDNF expression in hippocampus following hypoxia-ischemia in neonatal rats. J Ethnopharmacol. 2015;172:124-32.

97. Wu Z, Zou Z, Zou R, Zhou X, Cui S. Electroacupuncture pretreatment induces tolerance against cerebral ischemia/reperfusion injury through inhibition of the autophagy pathway. Mol Med Rep. 2015;11(6):4438-46.

98. Ting $Z$, Jianbin $Z$, Luqi $H$. Protective effect of electroacupuncture on neurons autophagy in perfusion period of cerebral ischemia. Neurosci Lett. 2017:661:41-5

99. Liu W, Shang G, Yang S, Huang J, Xue X, Lin Y, et al. Electroacupuncture protects against ischemic stroke by reducing autophagosome formation and inhibiting autophagy through the mTORC1-ULK1 complexBeclin1 pathway. Int J Mol Med. 2016;37(2):309-18.

100. Jung YS, Lee SW, Park JH, Seo HB, Choi BT, Shin HK. Electroacupuncture preconditioning reduces ROS generation with NOX4 down-regulation and ameliorates blood-brain barrier disruption after ischemic stroke. J Biomed Sci. 2016;23:32.

101. Xu H, Zhang Y, Sun H, Chen S, Wang F. Effects of acupuncture at GV20 and ST36 on the expression of matrix metalloproteinase 2, aquaporin 4 , and aquaporin 9 in rats subjected to cerebral ischemia/reperfusion injury. PLOS ONE. 2014;9(5):e97488.

102. Lin R, Yu K, Li X, Tao J, Lin Y, Zhao C, et al. Electroacupuncture ameliorates post-stroke learning and memory through minimizing ultrastructural brain damage and inhibiting the expression of MMP-2 and MMP-9 in cerebral ischemia-reperfusion injured rats. Mol Med Rep. 2016;14(1):225-33.

103. Li J, He J, Du Y, Cui J, Ma Y, Zhang X. Electroacupuncture improves cerebral blood flow and attenuates moderate ischemic injury via Angiotensin II its receptors-mediated mechanism in rats. BMC Complement Altern Med. 2014;14:441.

104. Zheng HZ, Jiang W, Zhao XF, Du J, Liu PG, Chang LD, et al. Electroacupuncture induces acute changes in cerebral cortical miRNA profile, improves cerebral blood flow and alleviates neurological deficits in a rat model of stroke. Neural Regen Res. 2016;11(12):1940-50.

105. Du Y, Shi L, Li J, Xiong J, Li B, Fan X. Angiogenesis and improved cerebral blood flow in the ischemic boundary area were detected after electroacupuncture treatment to rats with ischemic stroke. Neurol Res. 2011;33(1):101-7.

106. Mao QJ, Chen BG. Effects of electroacupuncture on microvascular ultrastructure and VEGF expression of the right cerebral cortex in focal cerebral ischemia/reperfusion injury rats. Zhen Ci Yan Jiu. 2012;37(6):476-81.

107. Xie C, Gao X, Luo Y, Pang Y, Li M. Electroacupuncture modulates stromal cell-derived factor-1alpha expression and mobilization of bone marrow endothelial progenitor cells in focal cerebral ischemia/reperfusion model rats. Brain Res. 2016;1648(Pt A):119-26.

108. Jia LY, Du YH, Li J, Pang B, Xu MY. Effects of electroacupuncture on morphology of neovascularization and expression of angiogenesis-related 
factors in ischemic brain tissue of cerebral ischemia rats. Zhen Ci Yan Jiu. 2019:44(10):715-21

109. Shi L, Cao HM, Li Y, Xu SX, Zhang Y, Zhang Y, et al. Electroacupuncture improves neurovascular unit reconstruction by promoting collateral circulation and angiogenesis. Neural Regen Res. 2017;12(12):2000-6.

110. Chang QY, Lin YW, Hsieh CL. Acupuncture and neuroregeneration in ischemic stroke. Neural Regen Res. 2018;13(4):573-83.

111. Lu L, Zhang XG, Zhong LL, Chen ZX, Li Y, Zheng GQ, et al. Acupuncture for neurogenesis in experimental ischemic stroke: a systematic review and meta-analysis. Sci Rep. 2016;6:19521.

112. Kim YR, Kim HN, Ahn SM, Choi YH, Shin HK, Choi BT. Electroacupuncture promotes post-stroke functional recovery via enhancing endogenous neurogenesis in mouse focal cerebral ischemia. PLoS ONE. 2014;9(2):e90000.

113. Luo D, Fan $X, M a C$, Fan T, Wang $X$, Chang $N$, et al. A study on the effect of neurogenesis and regulation of GSK3beta/PP2A expression in acupuncture treatment of neural functional damage caused by focal ischemia in MCAO rats. Evid Based Complement Alternat Med. 2014;2014:962343.

114. Acupuncture. National Institutes of health consensus development conference statement. Dermatol Nurs. 2000;12(2):126-33.

115. Chen L, Fang J, Ma R, Gu X, Chen L, Li J, et al. Additional effects of acupuncture on early comprehensive rehabilitation in patients with mild to moderate acute ischemic stroke: a multicenter randomized controlled trial. BMC Complement Altern Med. 2016;16(1):226.

116. Zhang S, Wu B, Liu M, Li N, Zeng X, Liu H, et al. Acupuncture efficacy on ischemic stroke recovery: multicenter randomized controlled trial in China. Stroke. 2015;46(5):1301-6.

117. Li RY, Wang RX, Xiao LY, Zhang YX, Pang ZX, Wang QX, et al. Effect of timing of acupuncture on limb dysfunction in patients with cerebral infarction: a multicenter prospective cohort pilot study. Zhongguo Zhen Jiu. 2021;41 (3):257-62.

118. Kim YR, Ahn SM, Pak ME, Lee HJ, Jung DH, Shin Y-I, et al. Potential benefits of mesenchymal stem cells and electroacupuncture on the trophic factors associated with neurogenesis in mice with ischemic stroke. Sci Rep. 2018:8(1):2044.

119. Zhao L, Zhou C, Li L, Liu J, Shi H, Kan B, et al. Acupuncture improves cerebral microenvironment in mice with Alzheimer's disease treated with hippocampal neural stem cells. Mol Neurobiol. 2017;54(7):5120-30.

120. Kang SK, Shin IS, Ko MS, Jo JY, Ra JC. Journey of mesenchymal stem cells for homing: strategies to enhance efficacy and safety of stem cell therapy. Stem Cells Int. 2012;2012:342968.

121. Ullah M, Liu DD, Thakor AS. Mesenchymal stromal cell homing: mechanisms and strategies for improvement. iscience. 2019:15:421-38.

122. Ley K, Laudanna C, Cybulsky MI, Nourshargh S. Getting to the site of inflammation: the leukocyte adhesion cascade updated. Nat Rev Immunol. 2007:7(9):678-89.

123. Karp JM, Teol GSL. Mesenchymal stem cell homing: the devil is in the details. Cell Stem Cell. 2009;4(3):206-16.

124. Mena H, Cadavid D, Rushing EJ. Human cerebral infarct: a proposed histopathologic classification based on 137 cases. Acta Neuropathol. 2004;108(6):524-30.

125. Uhlendorf TL, Nuryyev RL, Kopyov AO, Ochoa J, Younesi S, Cohen RW, et al. Efficacy of two delivery routes for transplanting human neural progenitor cells (NPCs) into the spastic Han-Wistar rat, a model of ataxia. Cell Transplant. 2017;26(2):259-69.

126. Xia L, Meng $Q, X i J$, Han $Q$, Cheng J, Shen J, et al. The synergistic effect of electroacupuncture and bone mesenchymal stem cell transplantation on repairing thin endometrial injury in rats. Stem Cell Res Ther. 2019;10(1):244

127. Schraufstatter IU, Khaldoyanidi SK, DiScipio RG. Complement activation in the context of stem cells and tissue repair. World J Stem Cells. 2015;7(8):1090-108.

128. Schraufstatter IU, DiScipio RG, Zhao M, Khaldoyanidi SK. C3a and C5a are chemotactic factors for human mesenchymal stem cells, which cause prolonged ERK1/2 phosphorylation. J Immunol. 2009;182(6):3827.

129. Chen T-Y, Wen T-K, Dai N-T, Hsu S-H. Cryogel/hydrogel biomaterials and acupuncture combined to promote diabetic skin wound healing through immunomodulation. Biomaterials. 2021;269:120608.
130. Yu H, Chen P, Yang Z, Luo W, Pi M, Wu Y, et al. Electro-acupuncture at conception and governor vessels and transplantation of umbilical cord blood-derived mesenchymal stem cells for treating cerebral ischemia/ reperfusion injury. Neural Regen Res. 2014;9(1):84-91.

131. Yang Z, Chen P, Yu H, Luo W, Pi M, Wu Y, et al. Combinatorial effects of conception and governor vessel electroacupuncture and human umbilical cord blood-derived mesenchymal stem cells on pathomorphologic lesion and cellular apoptosis in rats with cerebral ischemia/ reperfusion. JTradit Chin Med. 2013:33(6):779-86.

132. Ahn SM, Kim YR, Shin YI, Ha KT, Lee SY, Shin HK, et al. Therapeutic potential of a combination of electroacupuncture and TrkB-expressing mesenchymal stem cells for ischemic stroke. Mol Neurobiol. 2019;56(1):157-73.

\section{Publisher's Note}

Springer Nature remains neutral with regard to jurisdictional claims in published maps and institutional affiliations.
Ready to submit your research? Choose BMC and benefit from:

- fast, convenient online submission

- thorough peer review by experienced researchers in your field

- rapid publication on acceptance

- support for research data, including large and complex data types

- gold Open Access which fosters wider collaboration and increased citations

- maximum visibility for your research: over $100 \mathrm{M}$ website views per year

At BMC, research is always in progress.

Learn more biomedcentral.com/submissions 